Supplement of Biogeosciences Discuss., 12, 13041-13067, 2015

http://www.biogeosciences-discuss.net/12/13041/2015/

doi:10.5194/bgd-12-13041-2015-supplement

(C) Author(s) 2015. CC Attribution 3.0 License.

(c) (1)

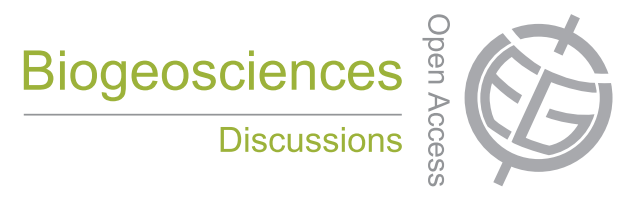

Supplement of

\title{
The root economics spectrum: divergence of absorptive root strategies with root diameter
}

D. Kong et al.

Correspondence to: D. Kong (deliangkong1999@126.com)

The copyright of individual parts of the supplement might differ from the CC-BY 3.0 licence. 


\section{Supporting information}

2 Figure S1. Frequency distribution of thickness of root EC for absorptive roots in the current (a)

3 and our previous study (Kong et al. 2014) (b). Root EC was the tissue outside the stele

4 including the epidermis plus cortex.

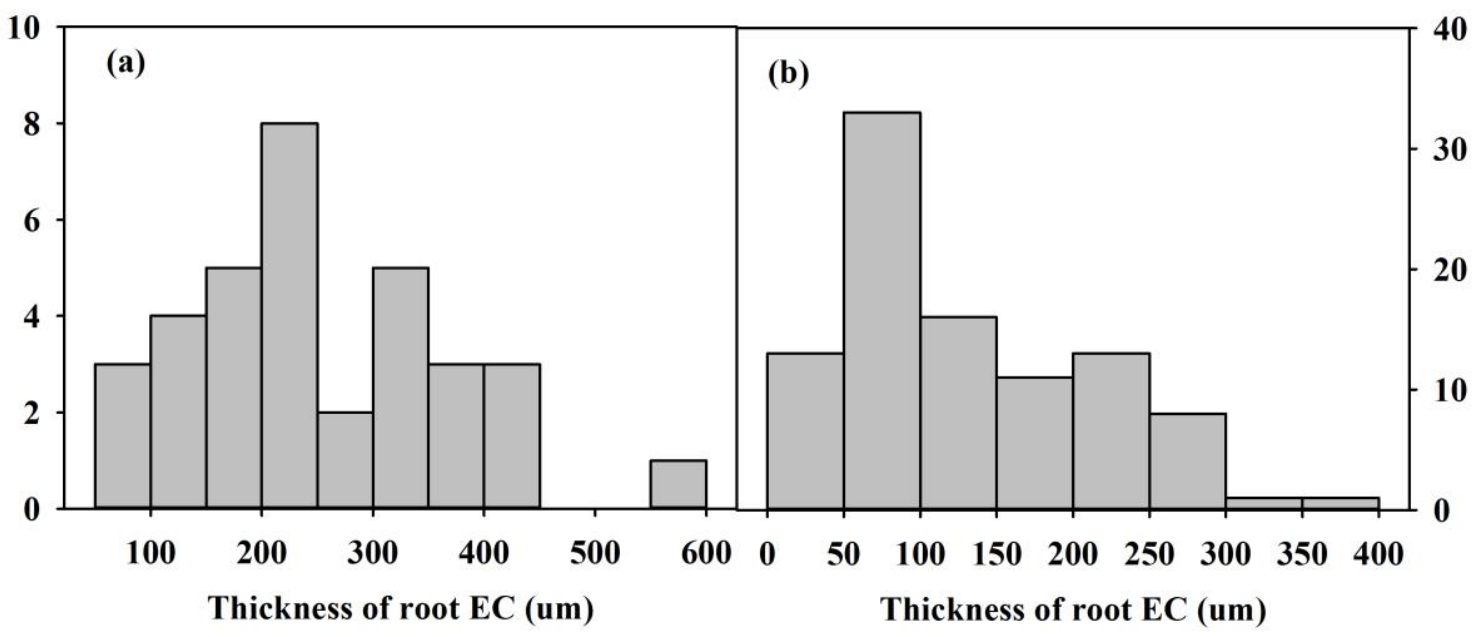

6

7

8

9 

excluded here.

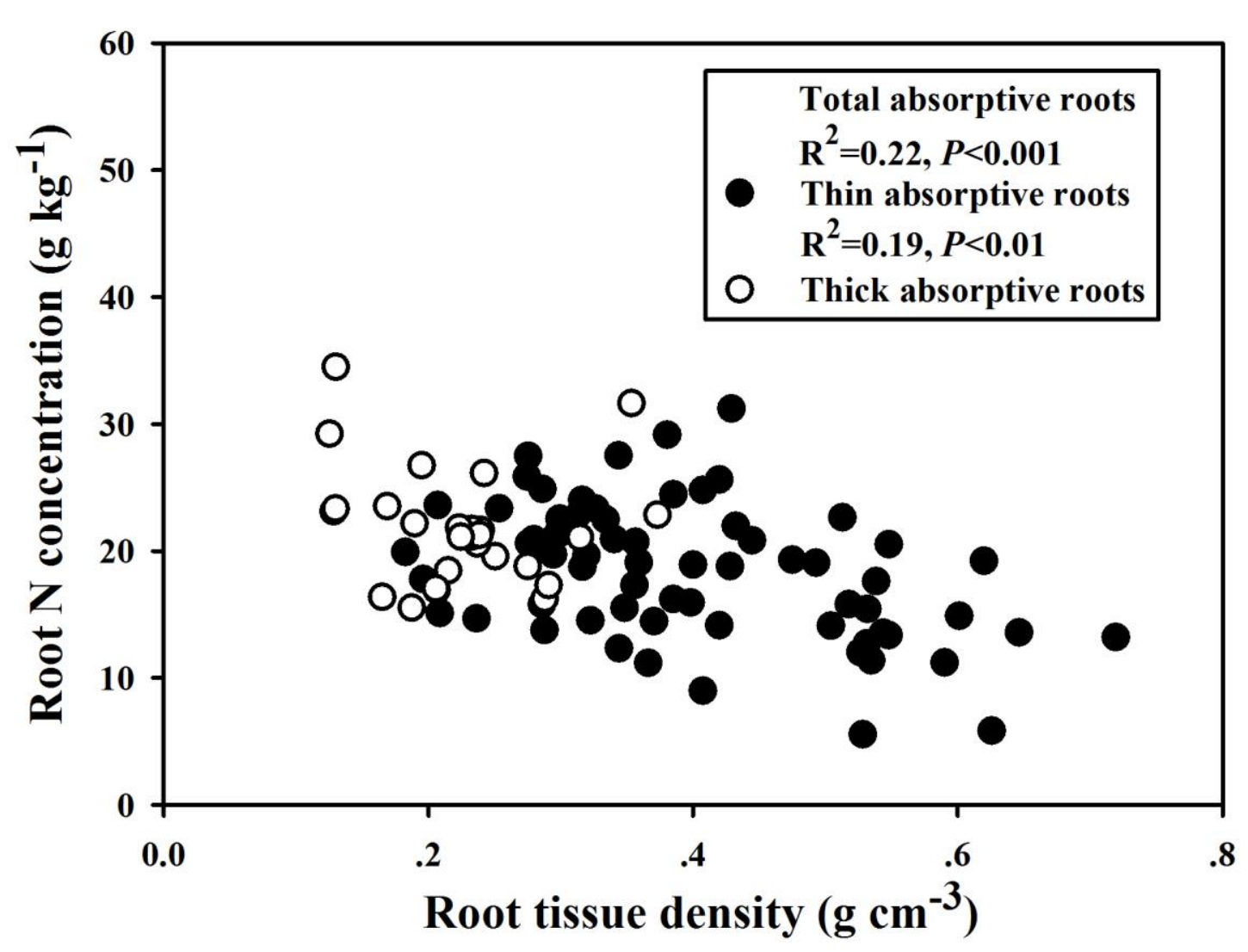

Figure S2. Relationships between root tissue density and root $\mathrm{N}$ concentration over the total, thin (solid circles) and thick (open circles) absorptive roots. Data were from woody species in our previous study (Kong et al. 2014) and two singular values of root $\mathrm{N}$ concentration were
22

4

\section{7.}

25

\section{6}



absorptive roots of our current study. The relationship was based on moving average method.

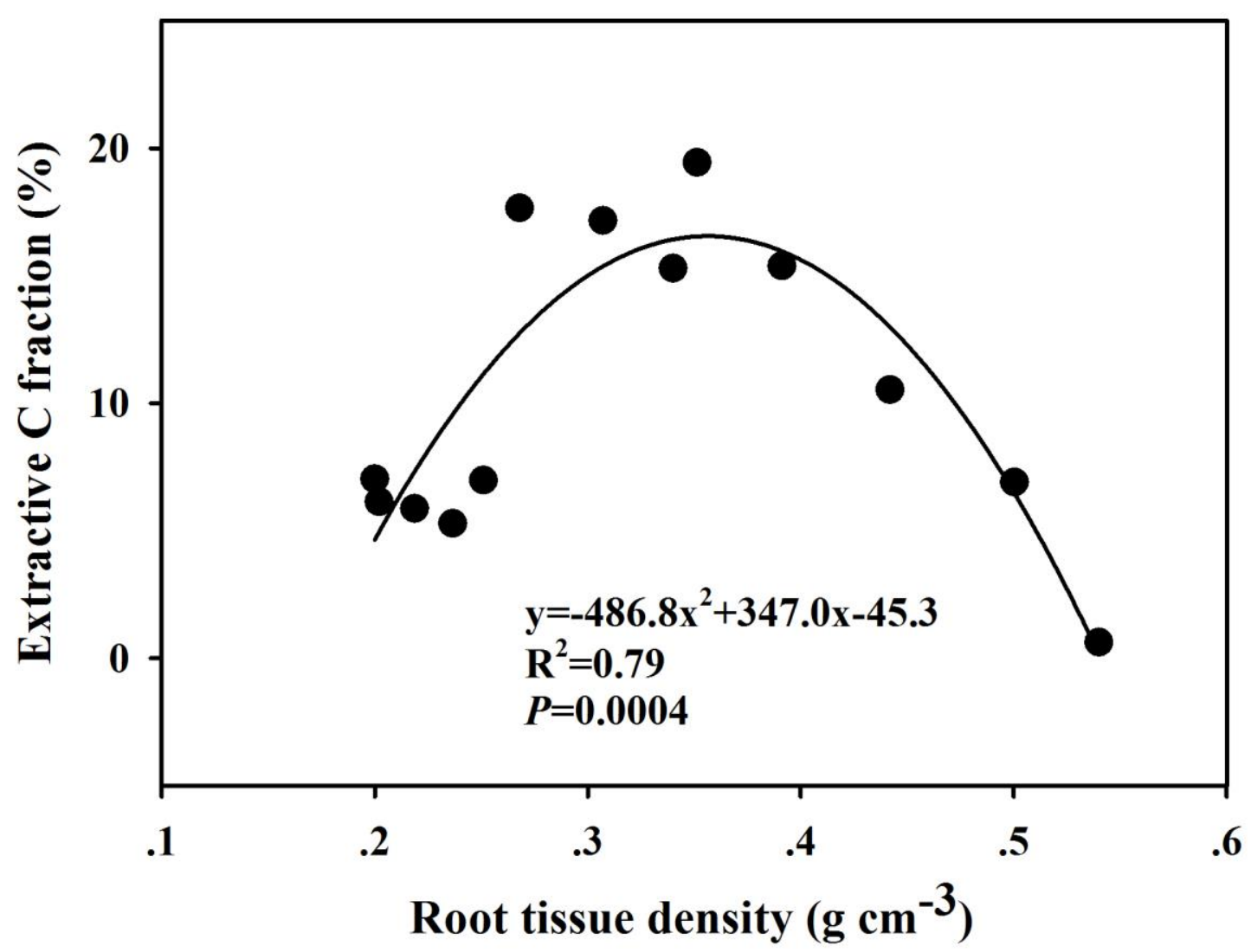

32 

epidermis plus cortex.

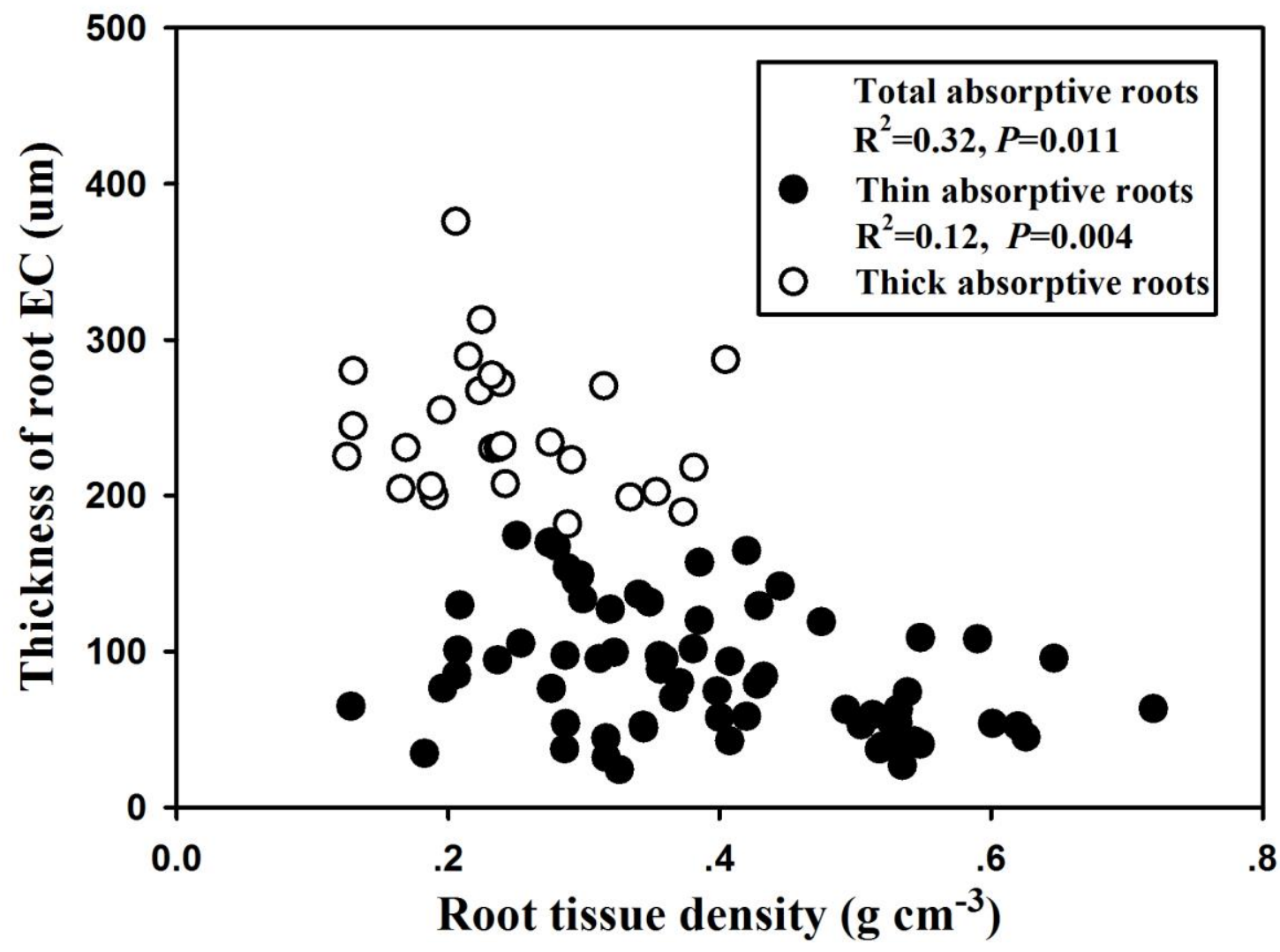


54 epidermis plus cortex.

\begin{tabular}{|c|c|c|c|c|}
\hline species & Root order & $\begin{array}{l}\text { Diameter } \\
(\mu \mathrm{m})\end{array}$ & $\begin{array}{l}\text { Root tissue } \\
\text { density }\left(\mathrm{g} \mathrm{cm}^{-3}\right)\end{array}$ & $\begin{array}{l}\text { Thickness of } \\
\text { root EC }(\mu \mathrm{m})\end{array}$ \\
\hline \multirow[t]{4}{*}{ D. dichotoma } & 1 & $196.80(9.01)$ & $0.60(0.05)$ & $70.5(3.10)$ \\
\hline & 2 & $255.59(20.94)$ & $0.47(0.06)$ & $81.06(5.16)$ \\
\hline & 3 & 412.34(27.99) & $0.50(0.08)$ & $119.45(7.25)$ \\
\hline & 4 & $623.32(128.96)$ & $0.50(0.04)$ & $169.86(19.09)$ \\
\hline \multirow[t]{5}{*}{ A. auriculiformis } & 1 & $286.47(12.46)$ & $0.22(0.02)$ & $98.81(4.85)$ \\
\hline & 2 & $362.03(18.26)$ & $0.27(0.03)$ & $134.19(9.51)$ \\
\hline & 3 & $509.85(34.16)$ & $0.34(0.06)$ & $168.68(16.51)$ \\
\hline & 4 & $552.44(22.39)$ & $0.33(0.03)$ & $160.63(13.40)$ \\
\hline & 5 & $852.78(29.42)$ & $0.35(0.03)$ & $146.21(0)$ \\
\hline \multirow[t]{5}{*}{ G. axillaris } & 1 & $539.9(15.82)$ & $0.36(0.02)$ & $216.76(5.43)$ \\
\hline & 2 & $630.63(20.14)$ & $0.37(0.02)$ & $242.84(9.46)$ \\
\hline & 3 & $659.87(32.32)$ & $0.43(0.03)$ & $150.6(19.45)$ \\
\hline & 4 & $687.50(19.21)$ & $0.60(0.04)$ & $201.07(23.67)$ \\
\hline & 5 & $1289.20(75.31)$ & $0.57(0.04)$ & $161.12(22.05)$ \\
\hline \multirow[t]{5}{*}{ C. lanceolata } & 1 & $558.09(18.42)$ & $0.21(0.02)$ & $221.51(8.28)$ \\
\hline & 2 & $488.53(12.37)$ & $0.25(0.02)$ & $186.1(6.53)$ \\
\hline & 3 & $532.01(21.27)$ & $0.24(0.02)$ & $194.69(9.81)$ \\
\hline & 4 & $773.20(48.83)$ & $0.31(0.03)$ & $235.91(34.07)$ \\
\hline & 5 & $1071.33(42.59)$ & $0.26(0.02)$ & $236.28(18.40)$ \\
\hline \multirow[t]{5}{*}{ P. baillonii } & 1 & $574.50(14.78)$ & $0.28(0.03)$ & $232.07(6.18)$ \\
\hline & 2 & $745.19(31.45)$ & $0.24(0.02)$ & $301.8(11.55)$ \\
\hline & 3 & $866.27(40.11)$ & $0.21(0.02)$ & $337.76(15.79)$ \\
\hline & 4 & $1021.15(79.76)$ & $0.26(0.04)$ & $363.79(23.80)$ \\
\hline & 5 & $1672.37(236.49)$ & $0.24(0.02)$ & $550.6(34.15)$ \\
\hline \multirow[t]{5}{*}{ E. chinense } & 1 & $748.89(39.21)$ & $0.28(0.02)$ & $266.12(16.59)$ \\
\hline & 2 & $1133.34(57.74)$ & $0.25(0.02)$ & $405.84(26.84)$ \\
\hline & 3 & $1240.00(46.05)$ & $0.27(0.02)$ & $426(22.00)$ \\
\hline & 4 & $2065.00(107.3)$ & $0.31(0.02)$ & $341.5(25.01)$ \\
\hline & 5 & $2460.00(229.35)$ & $0.29(0.02)$ & $364(12.89)$ \\
\hline \multirow[t]{5}{*}{ C. chinensis } & 1 & $982.23(27.63)$ & $0.20(0.03)$ & $339.17(11.75)$ \\
\hline & 2 & $1133.75(89.98)$ & $0.25(0.03)$ & $275(16.47)$ \\
\hline & 3 & $1170.00(67.21)$ & $0.49(0.02)$ & $393.19(24.46)$ \\
\hline & 4 & 1815.72(179.61) & $0.36(0.02)$ & $347.15(73.75)$ \\
\hline & 5 & 2766.67(120.19) & $0.33(0.03)$ & $353.34(20.47)$ \\
\hline
\end{tabular}

